\title{
Study on rare and endangered plants under climate: maxent modeling for identifying hot spots in northwest China
}

Hua Zhang ${ }^{1 * i D}$, Haoxiang Zhao ${ }^{1 \mathrm{iD}}$

${ }^{1}$ Northwest Normal University, China

\section{FOREST ECOLOGY}

\section{ABSTRACT}

Background: Climate warming has caused substantial changes in temporal and spatial environmental patterns. The study on hot spots of rare and endangered plants in Northwest China under predicted climate change can provide a scientific reference for the restoration and reconstruction of those degraded habitats, as well as the improvement of the protection system in Northwest China.

Results: Based on MaxEnt algorithm, 813 effective distribution records and 11 environmental factor variables of rare and endangered plants in Northwest China, this study identified the changes of biodiversity hotspots of rare and endangered plants in Northwest China under predicted climate change. The results showed that: (1) the prediction accuracy of MaxEnt model is high, the area under the curve (AUC) is 0.876 , and the total suitable area for potential geographical distribution of rare and endangered plants in Northwest China is $137.96 \times 104 \mathrm{~km}^{2}$, mainly including Western and Southwestern Xinjiang, Southern Gansu, parts of Eastern and Southern Qinghai Province, and Southern Shaanxi Province; (2) altitude, temperature and precipitation are the main environmental factors affecting the hot spots of rare and endangered plants in Northwest China; (3) under four climate change scenarios in the future, with the increase of emission scenarios from low to high forcing, Xinjiang would have the most obvious loss of hot spots of rare and endangered plants in Northwest China, and the most obvious increase of which would occur in Qinghai and Gansu provinces.

Conclusion: Under the climate change scenario in the future, with the emission scenario increasing from low forcing to high forcing, the most obvious loss of the hot spots of rare and endangered plants in Northwest China happens in Xinjiang Province, and that of the most obvious increase occurs in Qinghai and Gansu provinces.

Keywords: Northwest China; rare and endangered plants; MaxEnt model; hot spots; climate change

\section{HIGHLIGHTS}

The most effective variable in the hot spots of rare and endangered plants in Northwest China is the mean diurnal air temperature range.

Our model predicted that the shift of habitat to higher latitudes would become gradually more significant during the intensification of climate warming.

The prediction model in 2070 showed that the hot spots of rare and endangered plants would decrease. The results of this study can provide scientific reference for the protection system of degraded habitats of rare and endangered plants in Northwest China.

ZHANG, H.; ZHAO, H. Study on rare and endangered plants under climate: maxent modeling for identifying hot spots in northwest China. CERNE, v. 27, e-102667, doi: 10.1590/01047760202127012667 


\section{INTRODUCTION}

Climate change has an important impact on ecological phenomena such as regional distribution and phenology of species hot spots, resulting in changes of species distribution patterns on different temporal and spatial scales, thus accelerating the speed of species extinction or prosperity (Alan Pounds et al., 2006). The regional distribution of species hot spots is affected by many factors, such as ecological characteristics of species and the interaction of biotic and abiotic factors (Mantyka-Pringle et al., 2013). In recent years, due to human being's overuse of resources, climate change and other factors, species have being losing their suitable habitats, thus threatening biodiversity (Ke and Fan, 2016). Biodiversity conservation is related to the existence and continuation of many species on earth, as well as the survival of human beings. Therefore, how to take effective measures to protect biodiversity has become an international focus (Pimm et al., 2014). Due to the uneven distribution of suitable habitats of species and the differences in the degree of the threats, the study on species hot spots has become a method to maximize the benefits of biodiversity conservation. The species hot spots advocated by Conservation International (CI) (Jennings, 2000; Keping, 2001)have attracted the attention of international community. Species hot spots can be identified through quantitative analysis on climate factors and the prediction of the impact of climate change on species hot spots distribution, which has become the key to biogeography and global change researches (Thomas et al., 2004)

In recent years, species distribution model has become an important way to identify species hot spots in researches worldwide. Among them, MaxEnt maximum entropy model, Biomod, generalized additive model(Fois et al., 2018), classification tree analysis, and artificial neural network included are the most used (Elith and Graham, 2009; Phillips and Dudík, 2008). Because Maxent resulted with high performance with small samples and uses only presence records, so it is very suitable for the study and modeling of species hot spots (Ahmed et al., 2015). As a quantitative analysis tool, the model uses a specific algorithm to identify species hot spots and projects them into the landscape, which includes endangered species (Matyukhina et al., 2014), invasive species in a narrow sense (Tang et al., 2019), ecological degradation process (Thapa et al., 2018) and forest retraction in a broad sense (Li et al., 2020). Even in the case of few species distribution records (<20) (Fois et al., 2018), accurate results can be predicted (Kumar and Stohlgren, 2009; Syfert et al., 2013). It enables researchers to identify the area (Bennett et al., 2019; Hu et al., 2019) with high ecological stability of species according to the predicted results, and finally infer the species distribution hot spots (Chan et al., 2011; Wisz et al., 2010).In recent years, many scholars have done more researches on biodiversty hot spots in different regions via MaxEnt model (Tan et al., 2019; Tang et al., 2019).

According to the list of rare and endangered plants in China (Volume 1) published by the State Environmental Protection Administration and the Institute of Botany of the
Chinese Academy of Sciences, There are 72 species of rare and endangered plants in Northwest China, accounting for $18.5 \%$ of the national protected plants (science press, 1987). Rare and endangered plants are important basis for the survival of natural vegetation communities and species, an important part of biodiversity, and has an important impact on the integrity of biodiversity in Northwest China. Northwest in China faces the most serious threats to biodiversity (Li et al., 2004). The study on hot spots of rare and endangered plants in Northwest China under predicted climate change can provide a theoretical reference for the protection of rare and endangered plants in Northwest China. Focusing on 72 species of rare and endangered plants in Northwest China, this paper identifies the hot spots of rare and endangered plants under predicted climate change via MaxEnt model. The study aims to: (1) identify the hot spots of rare and endangered plants in Northwest China under current climatic conditions. (2) Explore the relationship between the distribution of hot spots and environmental factors, and explore the important environmental factors that limit the distribution of hot spots. (3) The hot spots of rare and endangered plants in Northwest China were predicted according to the global climate change scenarios of the future (2070s). The results of this study can provide scientific reference for the restoration, reconstruction and protection system of degraded habitats of rare and endangered plants in Northwest China.

\section{MATERIAL AND METHODS}

\section{Study area}

Northwest China is located in the interior of Eurasia with a geographical location of $73^{\circ} 26^{\prime}-114^{\circ} 06^{\prime} \mathrm{E}$ and $31^{\circ} 33^{\prime}-$ $49^{\circ} 11^{\prime} \mathrm{N}$. It covers an area of about $309 \times 104 \mathrm{~km}^{2}$, including the Xinjiang Uygur Autonomous Region, Gansu and Qinghai provinces, Ningxia Hui Autonomous Region and Shaanxi Province, with mainly plateaus, basins, mountains, deserts and Gobi, including Tianshan Mountains, Qilian Mountains, Taklimakan Desert, Loess Plateau, etc., as well as rivers and lakes (mainly inland rivers and lakes), including Tarim River, Weihe River, Yili River, Qinghai Lake, etc. Its annual range and diurnal range of temperature are very large, with abundant solar energy resources, drought and little rain. It is the driest area in China, with scarce rainfall in most areas and the annual precipitation of below $400 \mathrm{~mm}$, decreasing from southeast and northwest to the middle area, and sparse vegetation, with mainly in steppes and deserts (He et al., 2020; Shi et al., 2007).

\section{Data of Distribution}

According to the list of rare and endangered plants in China (Volume 1) published by the State Environmental Protection Administration and the Institute of Botany of the Chinese Academy of Sciences, there are 72 rare and endangered plant species in Northwest China. The current data of distribution of rare and endangered plants in 
Northwest China were collected from the Chinese Virtual

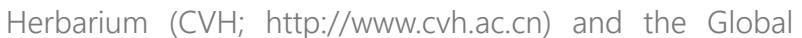
Biodiversity Information Facility (GBIF; http://www.gbif. org). We deleted some duplicate data points and data with incomplete longitude and latitude coordinate information and finally, a total of 813 records of rare and endangered plants in Northwest China were obtained (Fig. 1) for MaxEnt model building.

\section{Environmental Variables and Processing}

The current climate data used in this study (19702000) come from the WorldClim database (http://www. worldclim.org/). The future climate data (2070a) are obtained based on the BCC-CSM2-MR climate system model developed by the National Climate Center (Wu et al., 2019). The model contains four emission scenarios proposed by the sixth International Coupled Models Comparison Program (CMIP6) (Tab. 1). This scenarios is developed on the basis of the typical concentration path (RCPs) scenario (Kok et al., 2019), with a spatial resolution of 2.5 arc minutes (approximately 5 $\mathrm{km}$ at the equator). The data contain 19 bioclimatic variables, which are obvious biologically significant and are usually used in species distribution and related ecological modeling (Tab. 2). The topographic data contain three variables: elevation, slope and aspect, which are derived from the world elevation data with a resolution of $2.5^{\prime}$ from the WorldClim database (http://www.worldclim.org/).

However, many related variables are spatially correlated. The high correlations between some of these variables may lead to inaccuracy and over-fitting problems (Moya et al., 2017). Pearson correlation analysis of 22 environmental variables was performed via ArcGIS 10.2. When the correlation coefficient of two climate variables was less than 0.80, all the relevant climate variables were retained, and when the correlation coefficient of two climate variables was greater than 0.80 , the climate variables with more important ecological significance were retained, we selected the climate variables that are important for the hot spots. A total eleven variables with coefficients greater than 0.8 were retained for prediction of the hot spots (Yang et al., 2013). Eleven variables that were the most meaningful for rare and endangered plants in Northwest China were retained (Tab. 3).

\section{Ensemble of the MaxEnt model}

We used MaxEnt software (version 3.4.1) to model the habitat suitability of rare and endangered plants in Northwest China. This software is considered to build some of the best performing models for forecasting species distribution with a limited number of records. From the MaxEnt model, the output map values range from 0 to 1 (0 least and 1 most suitable species probability pixels) (Phillips et al., 2006). In our models, $75 \%$ of the occurrence records were used for training whereas $25 \%$ of the records were used for testing the model (Sunil et al., 2016), The background points and the number of iterations were set at no more than 10,000 and 1000, respectively. The ensemble processes were repeated in a ten-fold cross-validation to improve the performance of the model (Li et al., 2016).

The default output of Maxent is in the logistic form, indicating the environmental suitability for rare and endangered plants in Northwest China with values ranging from 0 to 1. For further analyses, the results of MaxEnt were imported into ArcGIS 10.2, and four categories of potential habitats were reclassified as follows: unsuitable $(<0.14)$, low suitable (0.14-0.34), high suitable (0.34-0.65) and most suitable (0.65-1.00) habitats.

\section{Evaluation of MaxEnt model}

A jackknife test of the contributions of environmental variables obtained from operation of the MaxEnt model was conducted to evaluate effects of environmental factors on distributions of Taiwania cryptomerioides in China. The MaxEnt model can track the environmental variables with high contributions and then increase the gain value by

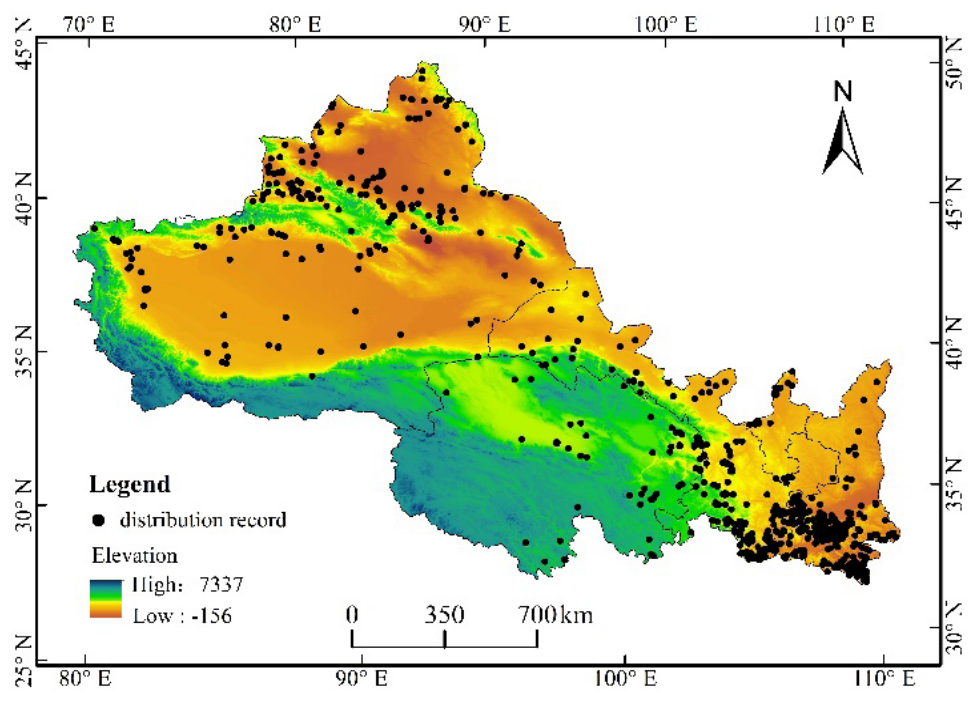

Fig. 1 General situation of the area and the distribution of rare and endangered plants in Northwest China. 
Tab. 1 Four emission scenarios (Sutton and Hawkins, 2020).

\begin{tabular}{cc}
\hline Emission & Description \\
\hline SSP5-8.5 & High obsessive-compulsive situation, Radiative forcing stabilizes at $8.5 \mathrm{~W} . \mathrm{m}^{2}$ in 2100 \\
SSP3-7.0 & Moderate to high obsessive-compulsive situation, Radiative forcing stabilizes at $7.0 \mathrm{~W} \cdot \mathrm{m}^{2}$ in 2100 \\
SSP2-4.5 & Moderate obsessive-compulsive situation, Radiative forcing stabilizes at $4.5 \mathrm{~W} . \mathrm{m}^{2}$ in 2100 \\
SSP1-2.6 & Low obsessive-compulsive situation, Radiative forcing stabilizes at 2.6 W.m $\mathrm{m}^{2}$ in 2100 \\
\hline
\end{tabular}

Tab. 2 Environmental variables.

\begin{tabular}{|c|c|c|c|}
\hline Variables & Description & Source & Unit \\
\hline Bio1 & Annual mean temperature & WorldClim & ${ }^{\circ} \mathrm{C}$ \\
\hline Bio2 & Mean diurnal range (mean of monthly (max temp - min temp)) & WorldClim & ${ }^{\circ} \mathrm{C}$ \\
\hline Bio3 & Isothermality (bio2/bio7) $\left({ }^{*} 100\right){ }^{\circ} \mathrm{C}$ & WorldClim & - \\
\hline Bio4 & Temperature seasonality (standard deviation * 100 & WorldClim & ${ }^{\circ} \mathrm{C}$ \\
\hline Bio5 & Max temperature of warmest month & WorldClim & ${ }^{\circ} \mathrm{C}$ \\
\hline Bio6 & Min temperature of coldest month & WorldClim & ${ }^{\circ} \mathrm{C}$ \\
\hline Bio7 & Temperature annual range (bio5-bio6) & WorldClim & ${ }^{\circ} \mathrm{C}$ \\
\hline Bio8 & Mean temperature of wettest quarter & WorldClim & ${ }^{\circ} \mathrm{C}$ \\
\hline Bio9 & Mean temperature of driest quarter & WorldClim & ${ }^{\circ} \mathrm{C}$ \\
\hline Bio10 & Mean temperature of warmest quarter & WorldClim & ${ }^{\circ} \mathrm{C}$ \\
\hline Bio11 & Mean temperature of coldest quarter & WorldClim & ${ }^{\circ} \mathrm{C}$ \\
\hline Bio12 & Annual precipitation & WorldClim & $\mathrm{mm}$ \\
\hline Bio13 & Precipitation of wettest month & WorldClim & $\mathrm{mm}$ \\
\hline Bio14 & Precipitation of driest month & WorldClim & $\mathrm{mm}$ \\
\hline Bio15 & Precipitation seasonality (coefficient of variation) & WorldClim & \\
\hline Bio16 & Precipitation of wettest quarter & WorldClim & $\mathrm{mm}$ \\
\hline Bio17 & Precipitation of driest quarter & WorldClim & $\mathrm{mm}$ \\
\hline Bio18 & Precipitation of warmest quarter & WorldClim & $\mathrm{mm}$ \\
\hline Bio19 & Precipitation of coldest quarter & WorldClim & $\mathrm{mm}$ \\
\hline
\end{tabular}

Tab. 3 Environmental variables in MaxEnt model

\begin{tabular}{cc}
\hline Variable & Description \\
\hline Bio2 & Mean diurnal air temperature range \\
Bio3 & Isothermality $($ Bio2/Bio $7 \times 100)$ \\
Bio6 & Max. temperature of the warmest month \\
Bio3 & Min. temperature of the coldest month \\
Bio5 & Isothermality (Bio2/Bio7 $\times 100)$ \\
Bio6 & Max. temperature of the warmest month \\
Bio3 & Isothermality (Bio2/Bio7 $\times 100)$ \\
Bio5 & Isothermality (Bio2/Bio7 $\times 100)$ \\
Bio6 & Max. temperature of the warmest month \\
\hline
\end{tabular}

modifying a single factor gradually, assigning the gain value to the environmental variables on which the factor depends, expressed as a percentage (Perkins-Taylor and Frey, 2020). The AUC score less than 0.5 indicates model discrimination, value ranging between 0.5 and 0.7 means low accuracy, value ranging from 0.7 to 0.9 indicates adequate accuracy, and value greater than 0.9 shows very high accuracy of the predicted output of the model (Swets, 1988).

The contribution rate and Jackknife test obtained from the operation of MaxEnt model are used to evaluate the importance of environmental factors affecting the distribution of rare and endangered plants in Northwest China.

\section{RESULTS}

\section{Distribution pattern of suitable habitats of rare and endangered plants in Northwest China under current climate conditions}

By applying the MaxEnt model, the model predicted the potential distribution of rare and endangered plants in Northwest China, with a training AUC value of 0.876 and a test AUC value of 0.849 , which indicates its high level of predictive performance (Fig. 2).

Among the environmental data used for the prediction of the MaxEnt model, MaxEnt constantly modifies the single evaluation factor coefficient adjustment model through iterative algorithms to calculate the contribution rates of 11 environmental factors to the prediction (Tab. 4). The top three environmental factors are mean diurnal air temperature range (Bio2, 51.6\%), precipitation of the wettest quarter (Bio16,10.1\%) and elevation (Elevation,7.4\%). The results of Jackknife method (Fig. 3) show that when only one single environmental factor is used, the three environmental factors that have the greatest influence on the normalized training gain are the daily ranges of mean diurnal air temperature range (Bio2), precipitation of the wettest quarter (Bio16) and min. temperature of the coldest month (Bio6), indicating that these environmental factors contain information that other environmental factors 
Tab. 4 Environmental variables and their contributions

\begin{tabular}{cc}
\hline Variable & Percent contribution (\%) \\
\hline Bio2 & 51.6 \\
Bio16 & 10.1 \\
Elevation & 7.4 \\
Bio5 & 6.3 \\
Bio19 & 5.5 \\
Bio7 & 5.4 \\
Bio6 & 3.8 \\
Slope & 2.8 \\
Bio15 & 2.8 \\
Bio3 & 2.2 \\
Aspect & 2.1 \\
\hline
\end{tabular}

do not have. Generally speaking, the main influencing factors of rare and endangered plants in Northwest China are elevation, air temperature factor (mean diurnal air temperature range and min. temperature of the coldest month) and precipitation factor variable (precipitation of the wettest quarter).

The relationship between the probability of existence of rare and endangered plants and environmental factors in Northwest China can be judged according to the response curve of environmental factors (Fig. 4). When the probability of existence is greater than 0.2 , the corresponding environmental factor value is the critical value of rare and endangered plants in Northwest China (Yan et al., 2020).

The mean diurnal air temperature range suitable for the growth of rare and endangered plants in Northwest China is $7.8-15.4^{\circ} \mathrm{C}$. The ranges of precipitation of the wettest quarter suitable for their growth are 7-10.9 mm and 45.2$513 \mathrm{~mm}$; The range of elevation suitable for their growth is -153-3560.0 m; And the range of min. temperature of the coldest month suitable for their growth is $-26-0.03^{\circ} \mathrm{C}$.

The hot spots of rare and endangered plants in Northwest China are calculated by MaxEnt model (Fig. 5).
Under current climate conditions, the total suitable area of the hot spots of rare and endangered plants in Northwest China is $137.96 \times 104 \mathrm{~km}^{2}$, with Xinjiang Province as the largest $\left(69.35 \times 104 \mathrm{~km}^{2}\right)$, followed by Gansu Province $\left(29.73 \times 104 \mathrm{~km}^{2}\right)$ and Shaanxi Province $\left(20.22 \times 104 \mathrm{~km}^{2}\right)$, and the total suitable habitat areas of Qinghai Province $\left(13.56 \times 104 \mathrm{~km}^{2}\right)$ and Ningxia Hui Autonomous Region $\left(5.1 \times 104 \mathrm{~km}^{2}\right)$ are relatively small. The hot spots of rare and endangered plants are mainly located in Western and Southwestern Xinjiang Province (There are some sporadic areas in the middle part), Southern Gansu Province, Eastern and Southern Qinghai Province, and Southern Shaanxi Province.

The most suitable area of the hot spots of rare and endangered plants in Northwest China is $14.05 \times 104 \mathrm{~km}^{2}$, with Shaanxi Province having the largest highly suitable habitat area $\left(8.47 \times 104 \mathrm{~km}^{2}\right)$, followed by Gansu Province $\left(4.46 \times 104 \mathrm{~km}^{2}\right)$, and which in Xinjiang Province $(0.81 \times 104 \mathrm{~km} 2)$, Qinghai Province $\left(0.26 \times 104 \mathrm{~km}^{2}\right)$ and Ningxia Hui Autonomous Region $\left(0.05 \times 104 \mathrm{~km}^{2}\right)$ are smaller. The most suitable area of the hot spots of rare and endangered plants mainly located in Western Xinjiang Province, Southern Gansu Province, Eastern Qinghai Province and Southern Shaanxi Province.

The highly suitable area of the hot spots of rare and endangered plants in Northwest China is $43.42 \times 104 \mathrm{~km}^{2}$, with Xinjiang Province having the largest highly suitable area $\left(18.19 \times 104 \mathrm{~km}^{2}\right)$, followed by Gansu Province $\left(12.38 \times 104 \mathrm{~km}^{2}\right)$ and Shaanxi Province $\left(6.62 \times 104 \mathrm{~km}^{2}\right)$. The highly suitable area in Shaanxi Province $\left(3.35 \times 104 \mathrm{~km}^{2}\right)$ and in Ningxia Hui Autonomous Region $\left(2.88 \times 104 \mathrm{~km}^{2}\right)$ are the smallest. The highly suitable area of the hot spots of rare and endangered plants are mainly located in Jimunai and Tacheng areas in the South of Xinjiang Province, the South of Gansu Province, Ningxia Hui Autonomous Region and Shaanxi Province. According to the calculation results of MaxEnt model, the proportion of highly suitable area of the hot spots of rare and endangered plants in Northwest

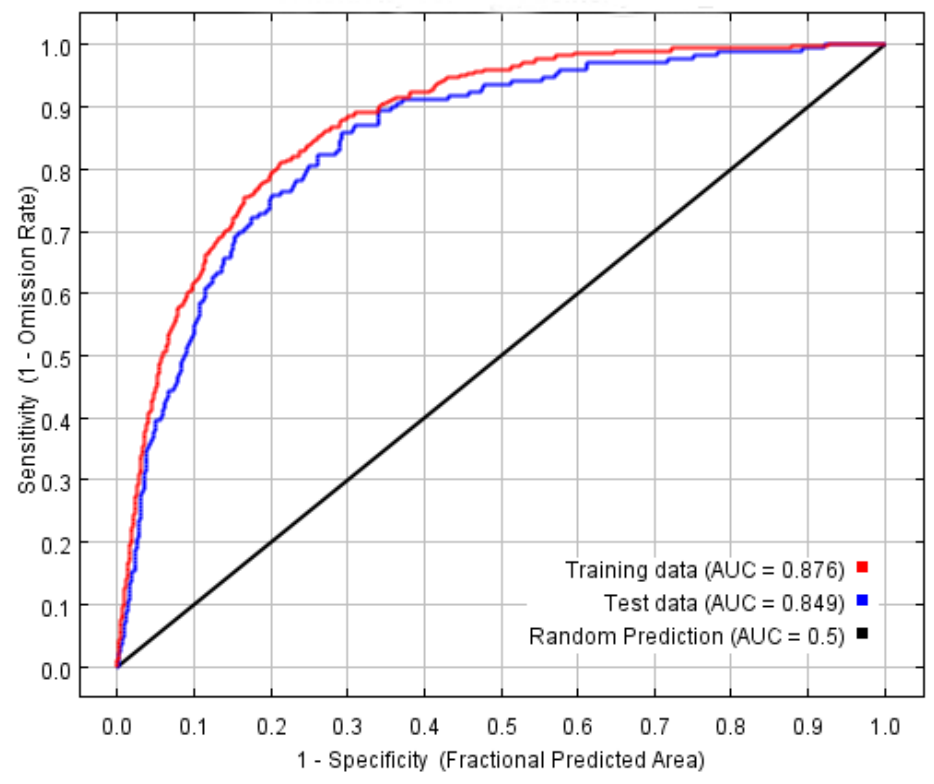

Fig. 2 Receiver operating characteristic curve of rare and endangered plants in Northwest China MaxEnt model. 


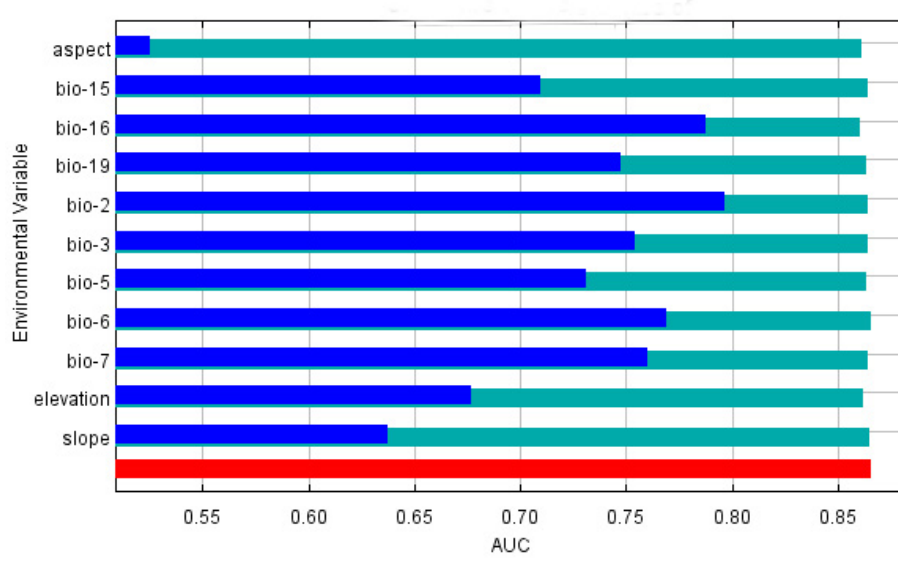

China is relatively small, showing the growth area of the hot spots of rare and endangered plants in Northwest China is relatively narrow.

\section{Future Change in Suitable Habitats}

Under four emission scenarios, MaxEnt model was used to identify the hot spots of rare and endangered plants in Northwest China. As a result, the hot spot distribution map of rare and endangered plants in Northwest China (Fig. 7) and the suitable areas of different grades of rare
Without variable $=$ With only variable With all variables
Fig. 3 The Jackknife test result of environmental factor for rare and endangered plants in Northwest China.

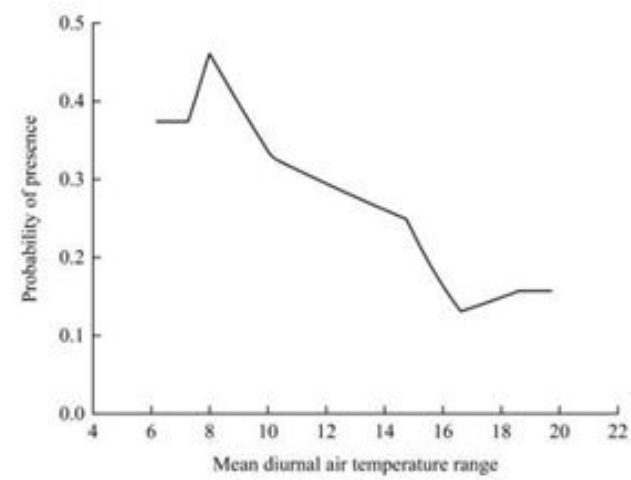

and endangered plants in provinces in Northwest China under different climatic conditions were obtained. As it can be seen from Fig. 5 and 7, the areas of different growth grades under the four emission scenarios in 2070 will change with various degrees compared to those under current climate conditions.

The highly suitable area of rare and endangered plants in Ningxia Hui Autonomous Region has increased in varying degrees. In the SSP1-2.6, the increase of the highly suitable area showed the largest; and the most suitable area also increased in varying degrees. There was no significant changes in the total suitable area, the range of the highly
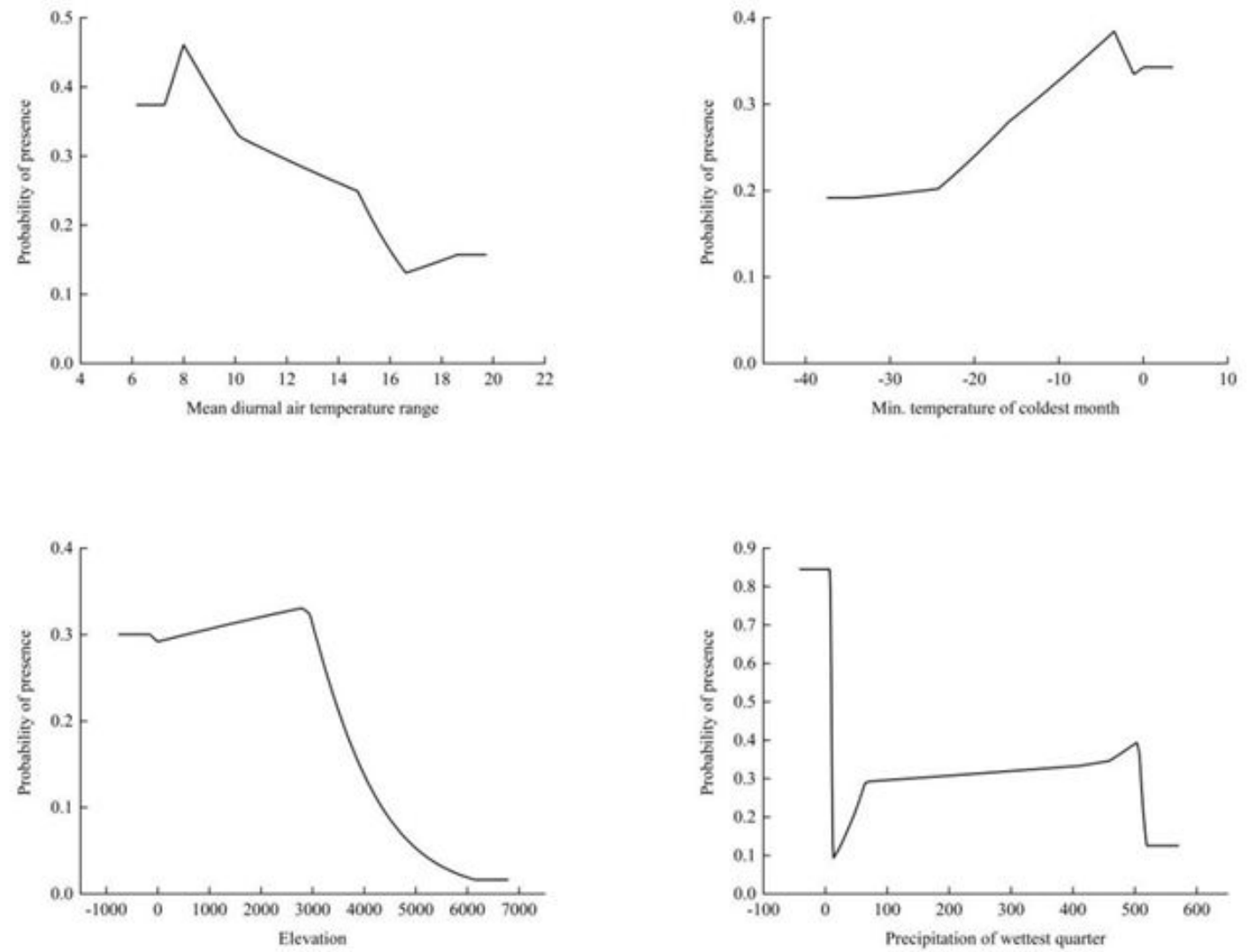

Fig. 4 Response curves of existence probability of rare and endangered plants in Northwest China. 


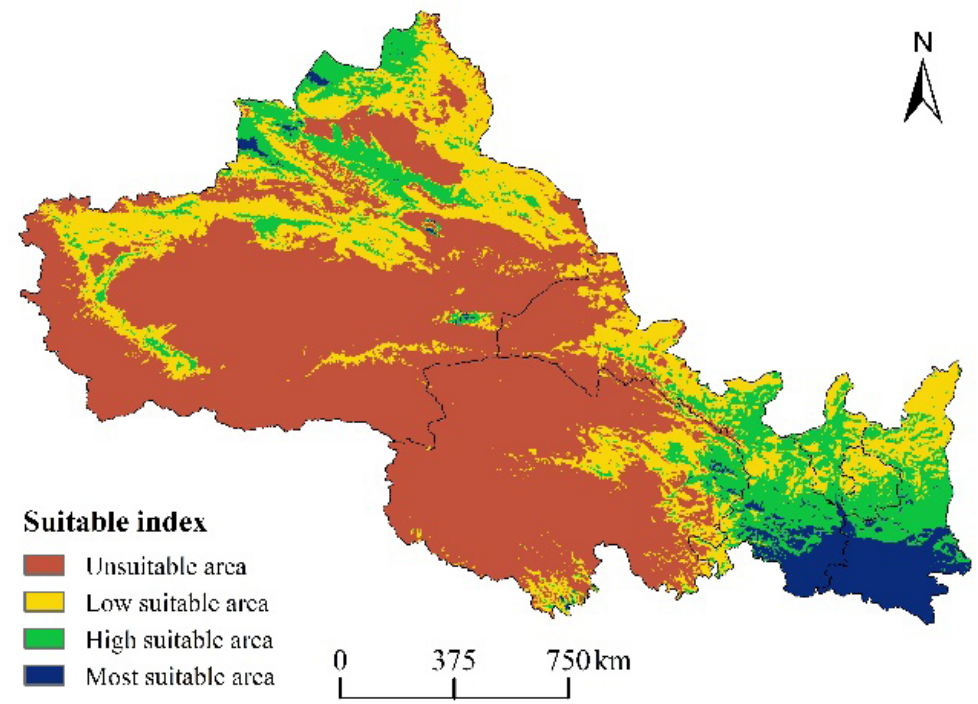

Fig. 5 Rare and Endangered Plant Hot spots in Northwest China.

suitable area expanded to the lowly suitable area, and some of the lowly and highly suitable areas were transformed into the most suitable areas.

The highly suitable area of rare and endangered plants in Northwest China varies in Shaanxi Province in different degrees. Under SSP1-2.6, the highly suitable area increases significantly, but under the other three emission scenarios, the changes of the highly suitable area

are not obvious compared to that under modern climate conditions. The most suitable area increases along with the changes of emission scenarios, with the largest increase under SSP5-8.5, while the total suitable area decreases significantly under SSP2-4.5, and the total suitable areas under other emission scenarios are almost the same as that under current climate conditions. The highly suitable area of rare and endangered plants in Gansu Province
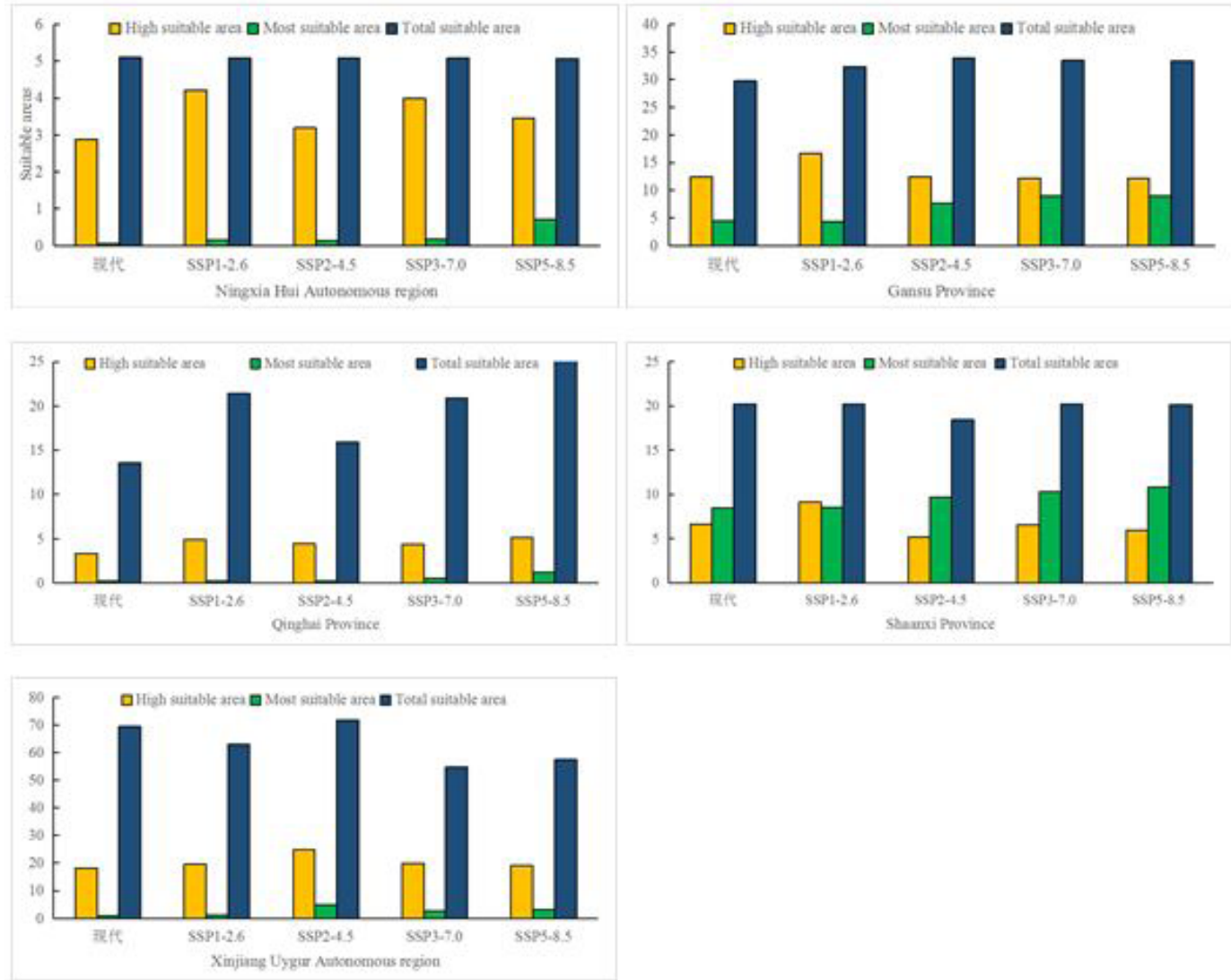

Fig. 6 Area of rare and endangered plants in Northwest China under Different Climatic Conditions $\left(\times 104 \mathrm{~km}^{2}\right)$. 

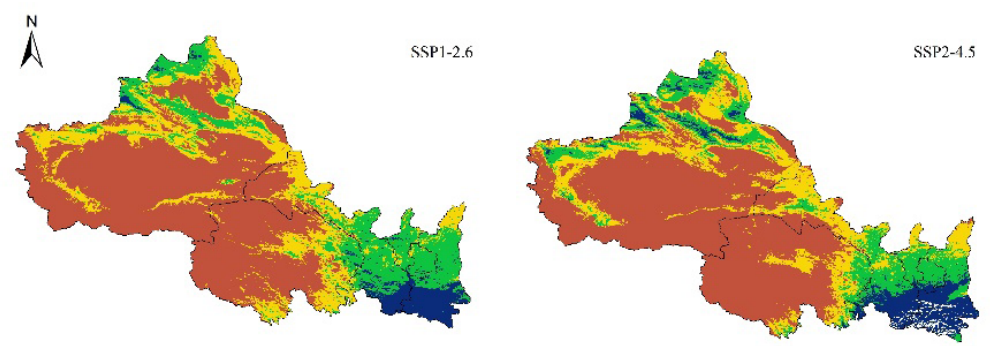

Fig. 7 Hot spots of rare and endangered plants in Northwest China under future climate change scenarios.

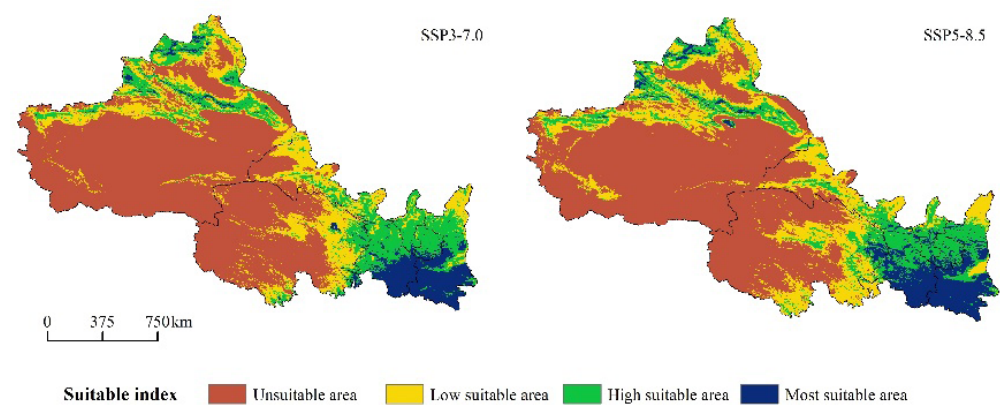

changes in varying degrees, showing a significant increase in SSP1-2.6. Under the other three emission scenarios, the highly suitable area do not change significantly compared to the current climate conditions, while under the other three emission scenarios, the highly suitable area does not change significantly compared to that under modern climate conditions. The highly suitable area of rare and endangered plants in Northwest China has increased significantly in Qinghai Province. The highly suitable area of rare and endangered plants in Northwest China is the largest, with the most obvious increase under the SSP5-8.5, and under the other three emission scenarios, the highly suitable area is not that significantly different. Under the SSP2-4.5 and SSP5-8.5, the most suitable areas both have a significant increase, while under the SSP5-8.5, the most suitable area is the largest and the increase is the most obvious. The highly suitable area of rare and endangered plants in Northwest China is increasing in Xinjiang Province. The highly suitable area of rare and endangered plants in Northwest China is the largest and the increase is the most obvious under the SSP2-4.5, and there is no significant difference among the other three emission scenarios, however, under the SSP2-4.5and SSP5-8.5, the highly suitable area of rare and endangered plants in Northwest China increases significantly, with the SSP2-4.5 having the largest area increased. Under the other three emission scenarios, the total suitable area has been losing in varying degrees in the west, south and middle part of Xinjiang Province.

\section{DISCUSSION}

\section{Significance of environmental variables in distribution modelling of hot spots of rare and endangered plants in Northwest China}

In this study, elevation and temperature are two important influencing factors of rare and endangered plants in Northwest China. Zhang Xiuhua (2018) studied the plant diversity and influencing factors of rare and endangered plants in Nature Reserve of Shandong Province. Altitude and temperature are the main factors affecting the species richness of rare and endangered plants at two spatial scales. Change of altitude gradient not only provides more diverse habitats for rare and endangered plants, but also plays a certain role in buffering climate change. The reason why rare and endangered plants are greatly affected by elevation is that, on one hand, the variation of elevation can better characterize the heterogeneity of habitats, and on the other hand, human activities in low altitude areas have a certain impact on rare and endangered plants. Lü Jiajia (2009) shows that the increase of temperature lead to the decrease of the richness of the most endangered species, and the distribution range of the most rare and endangered plants tends to decrease along with the increase of annual precipitation. This also well explains the reason why temperature has an important influence on rare and endangered plants in Northwest China, but in this study, the influence of precipitation on endangered plants in Northwest China is less than that of temperature. The reason for the difference between this study and previous studies is that this study takes the northwest region as the study area while the previous researches are nationwide, indicating that the influencing factors of rare and endangered plants are limited by regional scale. Some studies show that precipitation is not an important factor affecting the survival of rare and endangered plants, and the results of this study are consistent with it (Georgopoulou et al., 2016).

\section{Changes of hot spots of rare and endangered plants in Northwest China under predicted climate change}

In this study, environmental factor variables under four different emission scenarios were used under predicted climate change and current climate conditions, and MaxEnt model was used to predict the changes of hot spots of rare 
and endangered plants in Northwest China under future climate change (Fig. 8). The prediction results show that under the four emission scenarios in 2070, compared with the hot spots of rare and endangered plants in Northwest China under current climate conditions, the loss of hot spots of rare and endangered plants in Northwest China shows the most obvious in Xinjiang Province, and the increase of which shows the most obvious in Qinghai and Gansu provinces. With the increase of emission scenarios from low forcing to high forcing, the loss of hot spots in Altay, Fuhai, Shaya and the Yeerqiang River basin in Southwestern Xinjiang becomes gradually serious, and the scope of hot spots in Jiuzhi, Banma, Golmud and Zaduo areas in Qinghai Province gradually expands. There is heterogeneity in the response of different species to climate change. Erasmus found that $78 \%$ of the species distribution in South Africa decreased under climate change, but $17 \%$ of that expanded (Erasmus et al., 2002).

Bezeng et al. (2017) simulated the potential changes of 162 non-native trees and shrubs in South Africa under predicted climate change. The results show that the range of some species is expected to expand to certain areas by 2070, and the results of this study are basically consistent with each other (Bezeng et al., 2017). Kolanowska et al. (2017) analyzed the response of 16 orchid species to climate change by niche modeling and climate tolerance similarity methods, and found that there was no general trend in the response of closely-related plants to climate change. The niche ranges of 12 orchid species from the same evolutionary branch in different geographical regions (Europe, Asia, Australia, South America and North America) will show both hot spot expansion and loss under future climate change scenarios(Kolanowska et al., 2017). Akyol et al. (2020) used MaxEnt model that predicted the potential distribution of Pinus pinea L., the result show that it will lose habitat and it will shift geographical distribution towards north and higher elevation sites (Akyol and Örücü, 2020). Our results show that the total suitable area of hot spots of rare and endangered plants in Northwest China will benefit from climate change. This statement might be better supported by their results.

\section{Distributional Shift of Centroid in Highly Suitable Area}

The centroid of the highly suitable area was shown in Fig. 9. The centroid of the most suitable area in the future shifted to the geographical location (105.24E, 34.50N) under SSP1-2.6, and to the position northwest further $(100.82 E, 36.93 N)$ under SSP2-4.5. The centroid of the most suitable area in the future was located at the position $(103.73 \mathrm{E}, 35.68 \mathrm{~N})$ and $(102.95 \mathrm{E}, 36.38 \mathrm{~N})$ under SSP37.0 and SSP5-8.5 respectively. In general, the shift of the centroid of the most suitable area showed a higher latitude and a northwest tendency under emission trajectories in the future (SSP1-2.6, SSP2-4.5, SSP3-7.0 and SSP5-8.5), and a relatively weak strength was found under the emission trajectory of a higher representative concentration.

MaxEnt model predicted that different species had different potentially-distributed suitable areas. The results under different scenarios did not show the same tendency. Engler studied the effects of climate change on 2,632 species of plants distributed in the main mountains of Europe, with results of showing that, by the middle and late 21 st century (2070-2100), over $80 \%$ suitable habitats of $36 \%-55 \%$ of alpine plants and $19 \%-46 \%$ of mountain plants had reduced (Engler et al., 2011). The results of this study are basically consistent with it. Therefore, analysis
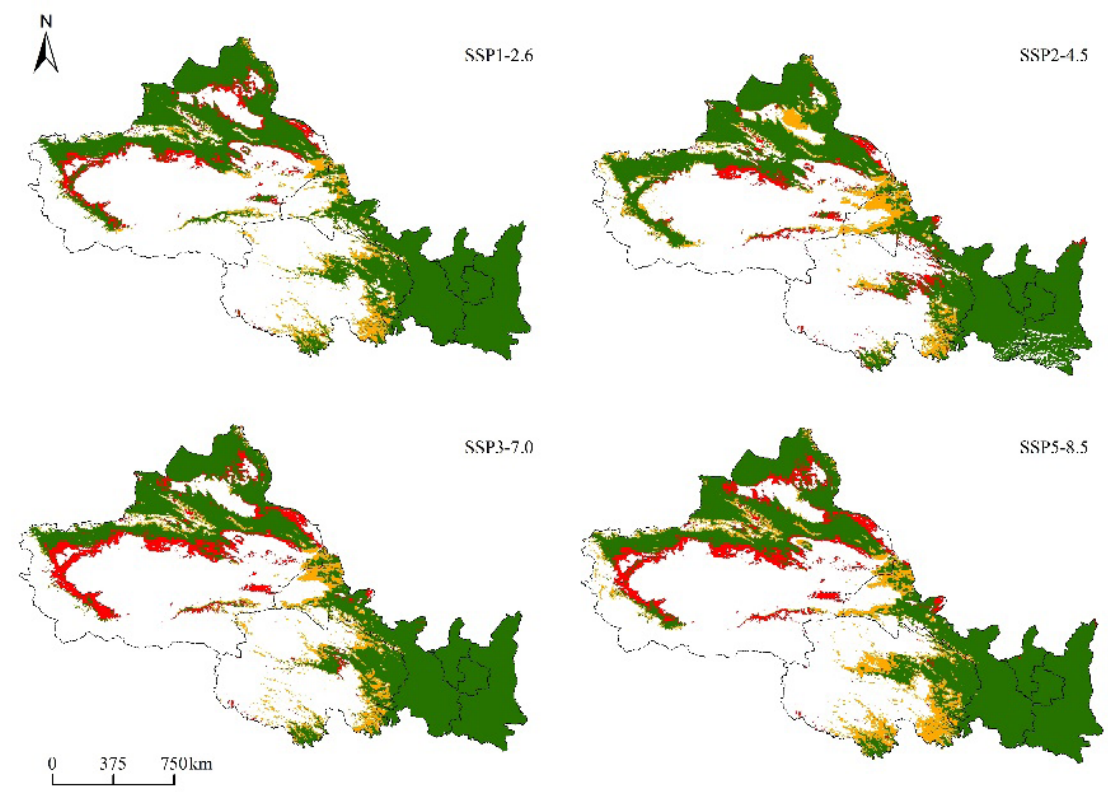

Legend

Disappeared area

Increased area Stable area

Fig. 8 Changes of potential geographical distribution of rare and endangered plants in Northwest China under climate change scenarios in the future. 


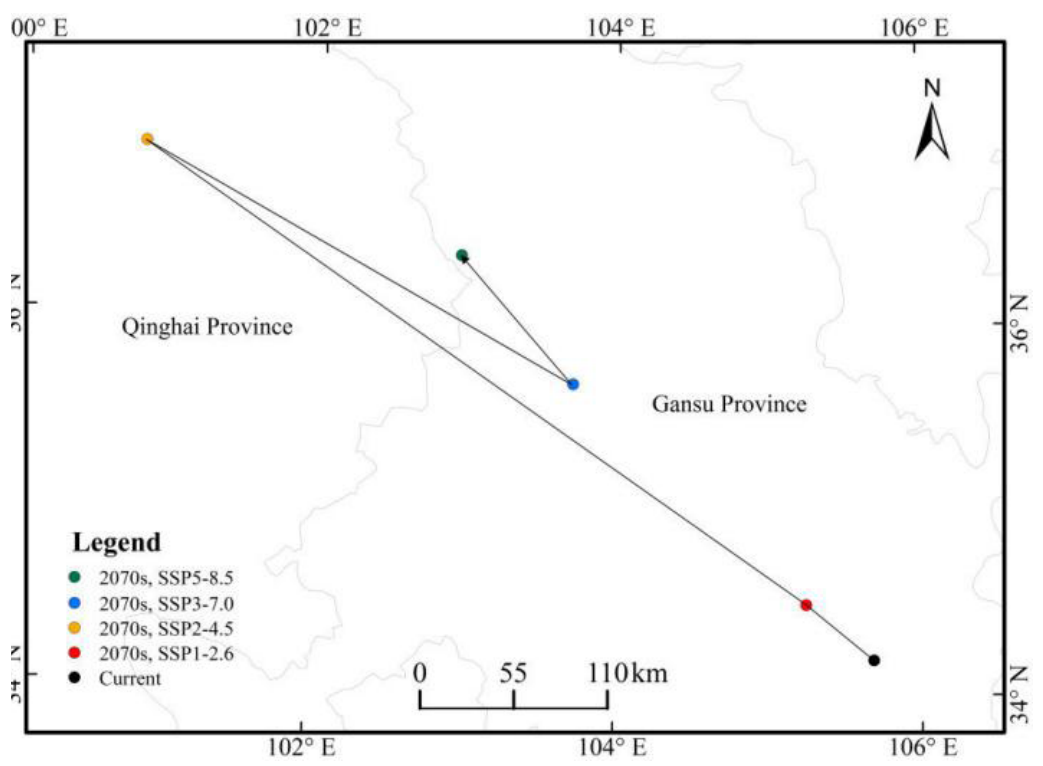

Fig. 9 Distributional shifts of centroid in the most suitable area under climate change. on the causes of the contraction of species distributions enables us to take possible measures to try to prevent or reverse negative trends. A large number of previous studies have shown that with climate warming (Wang et al., 2020), suitable habitats for species are facing the trend of shrinking and transferring to areas of high latitude or high altitude (Liu et al., 2019).

This study only uses the environmental factor variables in the period from 2060 to 2080 . Therefore, in the future researches on species hotspots under climate change scenarios, multiple research periods can be selected, as a result, the overall change trend of the hot spots of the research objects can be obtained.

\section{CONCLUSION}

Based on MaxEnt model, this study uses the environmental factor variables of four different emission scenarios under predicted climate change to identify the hot spots of rare and endangered plants in Northwest China, combined with current climatic conditions. The results show that the main influencing factors are elevation, air temperature factor (mean diurnal air temperature range and min temperature of the coldest month) and precipitation factor variable (precipitation of the wettest quarter). The hot spots of rare and endangered plants in Northwest China are mainly located in Western and Southwestern Xinjiang Province (There are some sporadic areas in the middle part), Southern Gansu Province, Eastern and Southern Qinghai Province, and Southern Shaanxi Province. Under the climate change scenario in the future, with the emission scenario increasing from low forcing to high forcing, the most obvious loss of the hot spots of rare and endangered plants in Northwest China happens in Xinjiang Province, and that of the most obvious increase occurs in Qinghai and Gansu provinces.

The potential impact of climate warming on the potential geographical distribution of species is mainly manifested in the shrinking or expansion and transfer of species hotspots, and the changes of the hot spots of rare and endangered plants in Northwest China under predicted climate change are also in line with this tendency.

\section{AUTHORSHIP CONTRIBUTION}

Project Idea: $\mathrm{HZ}$

Funding: $\mathrm{HZ}$

Database: $\mathrm{HZ}$

Processing: $\mathrm{HZ}, \mathrm{HZ}$

Analysis: $\mathrm{HZ}, \mathrm{HZ}$

Writing: $\mathrm{HZ}, \mathrm{HZ}$

Review: HZ

\section{REFERENCES}

Ahmed, S.E, Mclnerny, G, O'Hara, K. Harper, R, Salido, L, Emmott S. Joppa, L.N. 2015. Scientists and software-surveying the species distribution modelling community. Diversity and Distributions 21, 258-267.

AKYOL, A.: ORUCU, O. K. Investigation and evaluation of stone pine (Pinus pinea L.) current and future potential distribution under climate change in Turkey. CERNE, v. 25, n. 4, p.415-423, 2019

Alan Pounds, J., Bustamante, M.R., Coloma, L.A., Consuegra, J.A., Fogden M.P.L., Foster, P.N., La Marca, E., Masters, K.L., Merino-Viteri, A., Puschendorf R., Ron, S.R., Sánchez-Azofeifa, G.A., Still, C.J., Young, B.E., 2006. Widespread amphibian extinctions from epidemic disease driven by global warming. Nature 439, 161-167.

Bennett, M., Marquet, P.A., Sillero-Zubiri, C., Marino, J., 2019. Shifts in habitat suitability and the conservation status of the Endangered Andean cat Leopardus jacobita under climate change scenarios. Oryx 53, 356-367.

Bezeng, B.S., Morales-Castilla, I., van der Bank, M., Yessoufou, K., Daru, B.H. Davies, T.J., 2017. Climate change may reduce the spread of non-native species. Ecosphere 8, e01694.

Chan, L.M., Brown, J.L., Yoder, A.D., 2011. Integrating statistical genetic and geospatial methods brings new power to phylogeography. Molecular phylogenetics and evolution 59, 523-537.

Elith, J., Graham, C.H., 2009. Do they? How do they? WHY do they? On finding reasons for differing performances of species distribution models. Ecography $32,66-77$ 
Engler, R., Randin, C.F., Thuiller, W., Dullinger, S., Zimmermann, N.E., Araujo M.B., Pearman, P.B., Lay, G.L., Piedallu, C., Albert, C.H., 2011. 21st century climate change threatens mountain flora unequally across Europe. Globa Change Biology 17, 2330-2341.

Erasmus, B.F.N., Van Jaarsveld, A.S., Chown, S.L., Kshatriya, M., Wessels, K.J. 2002. Vulnerability of South African animal taxa to climate change. Global Change Biology 8, 679-693.

Fois, M., Cuena-Lombraña, A., Fenu, G., Bacchetta, G., 2018. Using species distribution models at local scale to guide the search of poorly known species: Review, methodological issues and future directions. Ecological Modelling 385, 124-132.

Georgopoulou, E., Djursvoll, P., Simaiakis, S.M., 2016. Predicting species richness and distribution ranges of centipedes at the northern edge of Europe. Acta Oecologica-international Journal of Ecology 74, 1-10

He, Y., Sheng, Z., He, M., 2020. Spectral analysis of gravity waves from near space high-resolution balloon data in Northwest China. Atmosphere 11, 133.

Hu, Z., Guo, K., Jin, S., Pan, H., 2019. The influence of climatic changes on distribution pattern of six typical Kobresia species in Tibetan Plateau based on MaxEnt model and geographic information system. Theoretical and Applied Climatology 135, 375-390.

Jennings, M.D., 2000. Gap analysis: concepts, methods, and recent results*. Landscape Ecology 15, 5-20.

Ke, Q.I., Fan, Z., 2016. Evaluation method for landscape connectivity based on graph theory:a case study of natural forests in Minqing County, Fujian Province. Acta Ecologica Sinica.

Keping, M.A., 2001. Hotspots Assessment and Conservation Priorities Identification of Biodiversity in China Should be Emphasized. Act a Phyt oecologi ca Sinica, 2001,25(1): 124-125.

Kok, K., Pedde, S., Gramberger, M., Harrison, P.A., Holman, I.P., 2019 New European socio-economic scenarios for climate change research: operationalising concepts to extend the shared socio-economic pathways. Regional Environmental Change 19, 643-654

Kolanowska, M., Kras, M., Lipi Naczk, A.M., 2017. Global warming not so harmful for all plants - response of holomycotrophic orchid species for the future climate change. entific Reports 7, 12704

Kumar, S., Stohlgren, T.J., 2009. Maxent modeling for predicting suitable habitat for threatened and endangered tree Canacomyrica monticola in New Caledonia. Journal of Ecology and the Natural Environment 1, 094-098.

Li, G., Du, S., Wen, Z., 2016. Mapping the climatic suitable habitat of oriental arborvitae (Platycladus orientalis) for introduction and cultivation at a global scale. Sci Rep 6, 30009

Li, Y., Li, M., Li, C., Liu, Z., 2020. Optimized maxent model predictions of climate change impacts on the suitable distribution of cunninghamia lanceolata in China. Forests 11, 302

Liu, J.; Yang, Y.; Wei, H.; Zhang, Q.; Zhang, X.; Zhang, X.; Gu, W. Assessing Habitat Suitability of Parasitic Plant Cistanche deserticola in Northwest China under Future Climate Scenarios. Forests 2019, 10, 823

Mantyka-Pringle, C.S., Martin, T.G., Rhodes, J.R., 2013. Interactions between climate and habitat loss effects on biodiversity: a systematic review and meta-analysis. Global Change Biology 19, 1642-1644.

Matyukhina, D., Miquelle, D., Murzin, A., Pikunov, D., Fomenko, P., Aramilev, V., Litvinov, M., Salkina, G., Seryodkin, I., Nikolaev, I., 2014. Assessing the influence of environmental parameters on Amur Tiger distribution in the Russian Far East Using a MaxEnt modeling approach. Achievements in the Life Sciences 8, 95-100.
Moya, W., Jacome, G., Yoo, C.K., 2017. Past, current, and future trends of red spiny lobster based on PCA with MaxEnt model in Galapagos Islands, Ecuador. Ecology and Evolution.

Perkins-Taylor, I.E., Frey, J.K., 2020. Predicting the distribution of a rare chipmunk (Neotamias quadrivittatus oscuraensis): comparing MaxEnt and occupancy models. Journal of Mammalogy, 4.

Phillips, S.J., Anderson, R.P., Schapire, R.E., 2006. Maximum entropy modeling of species geographic distributions. Ecological Modelling 190, 231-259.

Phillips, S.J., Dudík, M., 2008. Modeling of species distributions with Maxent: new extensions and a comprehensive evaluation. Ecography 31, 161-175.

Pimm, S.L, Jenkins, CN. Abell, R. Brooks, TM. Gittleman, J.L., Joppa, L.N., Raven P.H., Roberts, C.M., Sexton, J.O., 2014. The biodiversity of species and their rates of extinction, distribution, and protection. Science 344, 1246752-1246752.

Shi, Y., Shen, Y., Kang, E., Li, D., Ding, Y., Zhang, G., Hu, R., 2007. Recent and future climate change in northwest China. Climatic change 80, 379-393.

Sunil, K., Yee, W.L., Neven, L.G., 2016. Mapping Global Potential Risk of Establishment of Rhagoletis pomonella (Diptera: Tephritidae) Using MaxEnt and CLIMEX Niche Models. Journal of Economic Entomology, 2043.

Sutton, R.T., Hawkins, E., 2020. ESD Ideas: Global climate response scenarios for IPCC AR6. Earth System Dynamics Discussions, 1-4.

Swets, J.A., 1988. Measuring the accuracy of diagnostic systems. Science $240,1285-1293$

Syfert, M.M., Smith, M.J., Coomes, D.A., 2013. The Effects of Sampling Bias and Model Complexity on the Predictive Performance of MaxEnt Species Distribution Models. PLOS ONE 8, e55158.

Tan, J., Li, A., Lei, G., Xie, X., 2019. A SD-MaxEnt-CA model for simulating the landscape dynamic of natural ecosystem by considering socio-economic and natural impacts. Ecological Modelling 410, 108783.

Tang, J., Li, J., Lu, H., Lu, F., Lu, B., 2019. Potential distribution of an invasive pest, Eu platypus parallelus, in China as predicted by Maxent. Pest management science $75,1630-1637$

Thapa, A., Wu, R., Hu, Y., Nie, Y., Singh, P., Khatiwada, J., Yan, L., Gu, X., Wei, F., 2018. Predicting the potential distribution of the endangered red panda across its entire range using MaxEnt modeling. Ecol Evol 8 (10)

Thomas, C.D., Cameron, A., Green, R.E., Bakkenes, M., Beaumont, L.J., Collingham, Y.'.., Erasmus, B.F., De Siqueira, M.F., Grainger, A., Hannah, L., 2004. Extinction risk from climate change. Nature $427,145-148$

Wang, G., Wang, C., Guo, Z., Dai, L., Wu, Y., Liu, H., Li, Y., Chen, H., Zhang Y., Zhao, Y., Cheng, H., Ma, T., Xue, F., 2020. Integrating Maxent model and landscape ecology theory for studying spatiotemporal dynamics of habitat Suggestions for conservation of endangered Red-crowned crane. Ecological Indicators 116, 106472

Wisz, M.S., Hijmans, R.J., Li, J., Peterson, A.T., Graham, C.H., Guisan, A., Group, N.P.S.D.W., 2010. Effects of sample size on the performance of species distribution models. Diversity \& Distributions 14, 763-773.

Wu, T., Lu, Y., Fang, Y., Xin, X., Li, L., Li, W., Jie, W., Zhang, J., Liu, Y., Zhang, L., 2019. The Beiiing Climate Center climate system model (BCC-CSM): The main progress from CMIP5 to CMIP6. Geoscientific Model Development 12, 1573-1600.

Yan, H., He, J., Zhao, Y., Zhang, L., Zhu, C., Wu, D., 2020. Gentiana macrophylla response to climate change and vulnerability evaluation in China. Global Ecology and Conservation 22

Yang, X.Q., Kushwaha, S.P.S., Saran, S., Xu, J., Roy, P.S., 2013. Maxent modeling for predicting the potential distribution of medicinal plant, Justicia adhatoda L. in Lesser Himalayan foothills. Ecological Engineering 51, 83-87. 